\title{
Holt-Oram syndrome: a clinical genetic study
}

\author{
R A Newbury-Ecob, R Leanage, J A Raeburn, I D Young
}

\begin{abstract}
A clinical and genetic study of the HoltOram syndrome (HOS) has been carried out in the United Kingdom involving 55 cases designated Holt-Oram syndrome, together with their parents and sibs. Data from the clinical assessment of both familial and isolated cases were used to define the HOS phenotype and to outline the spectrum of abnormalities, especially factors affecting severity. Skeletal defects affected the upper limbs exclusively and were bilateral and asymmetrical. They ranged from minor signs such as clinodactyly, limited supination, and sloping shoulders to severe reduction deformities of the upper arm (4.5\%). The radial ray was predominantly affected and the left side was more severely affected than the right. All affected cases showed evidence of upper limb involvement. Cardiac defects were seen in $95 \%$ of familial cases and included both atrial septal defect (ASD, $34 \%$ ) and ventricular septal defect (VSD, $25 \%$ ); $39 \%$ had only ECG changes. Cardiac involvement ranged from asymptomatic conduction disturbances to multiple structural defects requiring surgery in infancy. Sudden death could be caused by heart block. Inheritance was autosomal dominant with $100 \%$ penetrance and no evidence of reduced fitness. Increasing severity occurred in succeeding generations consistent with anticipation.

(F Med Genet 1996;33:300-307)
\end{abstract}

Key words: Holt-Oram syndrome; heterogeneity; maternal effect; anticipation.

Several heart-hand syndromes have been identified of which the Holt-Oram (HOS) is the best known. The first formal report by Holt and Oram in $1960^{1}$ was based on a four generation family in which the main skeletal lesion was a triphalangeal thumb; the heart defect was a secundum atrial septal defect (ASD). There was also an unusual cardiac arrhythmia and evidence of hypoplastic peripheral vessels. Of nine subjects, four were confirmed as affected and five (not examined) were affected by history. ASD was suspected in four but only confirmed in one case. Electrocardiography (ECG) showed a variety of abnormalities including a long PR interval, sinus bradycardia, nodal escape, and atrial fibrillation. Three family members had a triphalangeal thumb. The thumb was absent in one subject and another had radial aplasia. One case had only a minor anomaly of the clavicle. Subsequent reports have included various combinations of upper limb abnormality and heart defect. ${ }^{2-6}$ The need to clarify the spectrum of abnormalities and to delineate the HOS phenotype led us to review the clinical features in our patients, and distinguish the clinical features most helpful for counselling purposes.

This study was carried out in conjunction with a genetic linkage study which has shown genetic heterogeneity in the Holt-Oram syndrome, with one gene (HOS1) being localised to chromosome 12 in five out of seven families. ${ }^{7}$ No phenotypic differences could be detected between the linked and unlinked families.

\section{Patients and methods}

The study was carried out between March 1991 and September 1993. Cases were ascertained by contacting clinical geneticists and paediatric cardiologists and through the support group $\mathrm{REACH}$, for children with upper limb deficiency. Patients and first degree relatives were visited at home by RNE. A detailed family history was taken as well as all relevant medical and surgical details. Patients were examined carefully for any skeletal abnormalities or dysmorphic features. Measurements were taken of the upper arm, lower arm, palm, thumb, and middle finger. Where possible portable electrocardiography was performed. Information was sought from $x$ rays, electrocardiograms (ECG), and cardiac ultrasound examinations previously undertaken.

In order to assess the severity of abnormalities, clinical examination data were recorded using a scoring system based on that devised by Gall et $a l^{8}$ and modified by Gladstone and Sybert $^{9}$ (table 1). Measurements were compared with age matched standards. ${ }^{10}$ Statistical analysis was carried out using MannWhitney/Kruskall Wallis and Spearman Rank Correlation.

\section{ASCERTAINMENT}

Sixty six affected subjects from 28 families were referred to the study. Twelve families had three or more affected members. There were 33 males and 33 females; their ages ranged from

Table 1 Severity score system

Skeletal abnormalities

0 No abnormality on physical or radiological examination

Minor abnormalities including reduced thenar eminence, clinodactyly, or hypoplasia of the thumb

Triphalangeal or aplastic thumbs. Radial/ulnar hypoplasia

3 Arms and forearms present but bone(s) missing

4 Phocomelia

Cardiac abnormalities

0 Asymptomatic with no physical findings

1 Asymptomatic murmur or conduction defect

2 Structural heart abnormality not requiring surgery

Structural heart abnormality not requiring surger

Lethal malformation 
Table 2 Details of cases referred to study March 1991-September 1993

\begin{tabular}{lr}
\hline Index cases & 66 \\
Relatives found to be affected during study & 6 \\
Total affected cases included in study & 72 \\
Personally examined & 57 \\
Dead & 5 \\
Unavailable or insufficient details & 8 \\
Total unaffected relatives & 59 \\
Total affected and unaffected & 131 \\
\hline
\end{tabular}

4 months to 70 years. Thirteen cases had no family history of HOS and are referred to in this study as isolated. Fifteen patients were not available for examination; these included five affected subjects who had died whose details were obtained from family history (5) and from case notes (2), PM details (2), and photographs (4). Twelve examined patients had not had ECG and echocardiography. Six relatives, thought previously to be unaffected, were found to be affected during the study examination. In total, 57 patients were examined. Details of the cases are given in table 2. Cases were included only if the heart and radial ray defects previously described in HOS were present in at least one affected family member. Two patients from one family who had upper limb abnormalities but no evidence of cardiac abnormality within the family were excluded from the study.

\section{Clinical features}

UPPER LIMB ABNORMALITIES (TABLE 3)

Familial cases

In all cases upper limb abnormalities were present and were clinically detectable. The radial ray was predominantly affected, with ulnar involvement only when the radius was also involved and with a lesser degree of severity. Transverse reduction defects were not seen.
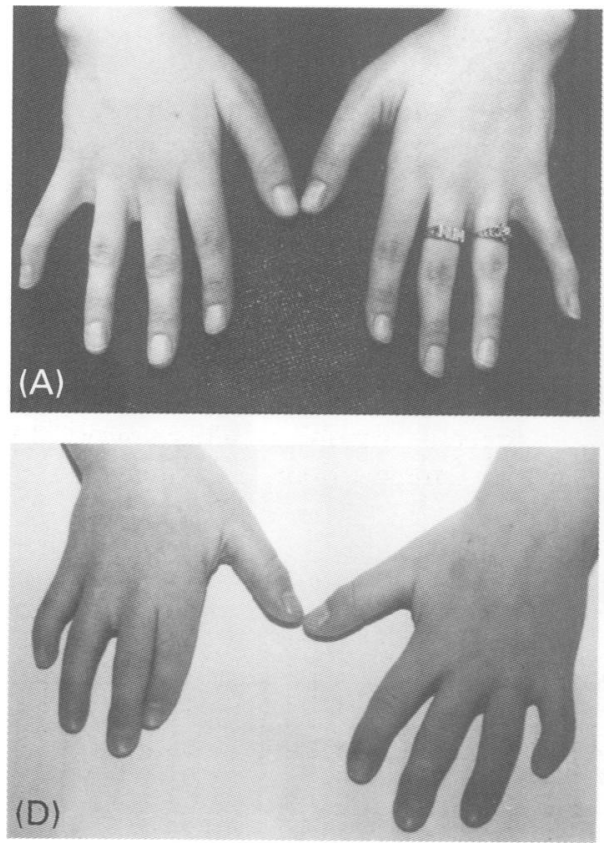

Figure 1 Typical hand abnormalities in HOS. Hands of four affected people showing (A) bilateral opposable triphalangeal thumbs, (B) right triphalangeal thumb, left absent thumb, (C) bilateral hypoplastic thumbs, and (D) normal thumbs with fifth finger clinodactyly and brachydactyly of the second to fifth fingers.
Table 3 Frequency and type of common upper limb and thorax abnormalities in 55 patients with HOS

\begin{tabular}{|c|c|c|}
\hline \multirow[t]{2}{*}{ Abnormality } & \multicolumn{2}{|c|}{ No affected (\%) } \\
\hline & $\begin{array}{l}\text { Familial } \\
n=44\end{array}$ & $\begin{array}{l}\text { Isolated } \\
n=11\end{array}$ \\
\hline \multicolumn{3}{|l|}{ Hand } \\
\hline $\begin{array}{l}\text { Thumb } \\
\text { Absent } \\
\text { Hypoplasia } \\
\text { Triphalangeal } \\
\text { Syndactyly } \\
\text { Long } \\
\text { Normal }\end{array}$ & $\begin{array}{r}19(43) \\
17(39) \\
8(18) \\
5(11) \\
6(14) \\
7(16)\end{array}$ & $\begin{array}{l}8(73) \\
4(36) \\
2(18) \\
2(18) \\
0 \\
0\end{array}$ \\
\hline Hypoplastic thenar eminence & $31(70)$ & $11(100)$ \\
\hline $\begin{array}{l}\text { Fingers } \\
\text { Clinodactyly } \\
\text { Brachydactyly } \\
\text { Hypoplasia } \\
\text { Absent } \\
\text { Syndactyly } \\
\text { Normal }\end{array}$ & $\begin{array}{r}28(64) \\
19(43) \\
7(16) \\
3(7) \\
4 \quad(9) \\
10(23)\end{array}$ & $\begin{array}{l}5(45) \\
9(82) \\
3(27) \\
2(18) \\
0\end{array}$ \\
\hline \multicolumn{3}{|l|}{ Lower arm } \\
\hline $\begin{array}{l}\text { Radius } \\
\text { Hypoplasia } \\
\text { Aplasia }\end{array}$ & $\begin{array}{l}18(41) \\
10(23)\end{array}$ & $\begin{array}{l}6(55) \\
3(27)\end{array}$ \\
\hline $\begin{array}{l}\text { Ulna } \\
\text { Hypoplasia } \\
\text { Aplasia }\end{array}$ & $\begin{array}{c}18(49) \\
0\end{array}$ & $\begin{array}{l}2(18) \\
4(36)\end{array}$ \\
\hline Limited supination & $27(61)$ & $5(45)$ \\
\hline Limited extension elbow & $22(50)$ & $7(64)$ \\
\hline Normal & $15(34)$ & $1 \quad(9)$ \\
\hline \multicolumn{3}{|l|}{ Upper arm } \\
\hline $\begin{array}{l}\text { Humerus } \\
\text { Hypoplasia } \\
\text { Abnormal head } \\
\text { Aplasia } \\
\text { Normal }\end{array}$ & $\begin{array}{r}20(45) \\
22(50) \\
0 \\
22(50)\end{array}$ & $\begin{array}{lr}8 & (73) \\
7 & (64) \\
1 & (9) \\
1 & (9)\end{array}$ \\
\hline \multicolumn{3}{|l|}{ Shoulder girdle } \\
\hline $\begin{array}{l}\text { Clavicles } \\
\text { Hypoplasia } \\
\text { Prominent acromioclavicular joint } \\
\text { Normal }\end{array}$ & $\begin{array}{l}33(78) \\
11(25) \\
10(23)\end{array}$ & $\begin{array}{l}7(64) \\
5(45) \\
2(18)\end{array}$ \\
\hline \multicolumn{3}{|l|}{ Thorax } \\
\hline Pectus excavatum & $18(41)$ & $1 \quad(9)$ \\
\hline Hypoplasia pectoralis major & $29(66)$ & $5(45)$ \\
\hline
\end{tabular}

Minor abnormalities, including hypoplasia of the thenar eminence, limited supination of the forearm, and narrow sloping shoulders, occurred without other evidence of skeletal involvement. Severe reduction abnormalities were found in two familial cases $(4 \cdot 5 \%)$. Fig 1 shows typical hand abnormalities in HOS.

Thumb

The thumb was the most commonly affected structure $(84 \%)$. In contrast to the largest previous study, ${ }^{2}$ no patients had involvement of the thumb only. Even mild thumb hypoplasia was accompanied by hypoplasia of the thenar eminence $(70 \%)$, limited supination of the forearm $(61 \%)$, or narrowing of the shoulders. Triphalangeal thumb was only found in eight patients $(18 \%) ; 19(43 \%)$ had absence of one or both thumbs. Other frequent thumb abnormalities included a hypoplastic or rudimentary thumb $(17,39 \%)$ or a long thumb owing to elongation of the proximal phalanx $(6,14 \%)$. Five patients $(11 \%)$ had syndactyly of the first and second digits and seven patients $(16 \%)$ had no detectable abnormality of the thumb. 


\section{Fingers}

Hand measurements showed reduced finger length in 19 cases (43\%), including four in whom no thumb abnormality was present. Hypoplasia of individual fingers $(16 \%)$ most commonly involved the index and middle fingers. Three patients had absence of one or more fingers. This occurred only where the thumb was also absent. Clinodactyly of the fifth finger was a common finding $(64 \%)$.

\section{Lower arm}

In the lower arm, radial hypoplasia was seen in 18 cases $(41 \%)$ and was invariably accompanied by a lesser degree of ulnar hypoplasia. No patients had involvement of the ulna only. Ten $(23 \%)$ had complete radial aplasia. The commonest functional abnormality was limited supination of the forearm seen in 27 cases $(61 \%)$. This was not always associated with radiological evidence of radioulnar synostosis but was sometimes associated with limited extension of the elbow.

\section{Upper arm}

Upper arm involvement leading to rhizomelic shortening was detected in almost half of all cases $(45 \%)$, including four cases with no obvious radial hypoplasia. Phocomelia was seen in two familial cases (4.5\%) (fig 2).

\section{Shoulder}

Proximal reduction defects were not present without distal defects, with the exception of shoulder abnormalities which were especially common $(77 \%)$, giving a characteristic appearance of narrow, sloping shoulders, this being because of the combination of short hypoplastic clavicles, hypoplasia of the head of the humerus, and decreased musculature. Alternatively, prominence of the lateral third of the clavicle and acromioclavicular joint gave a bony prominence to the shoulder (fig 3).
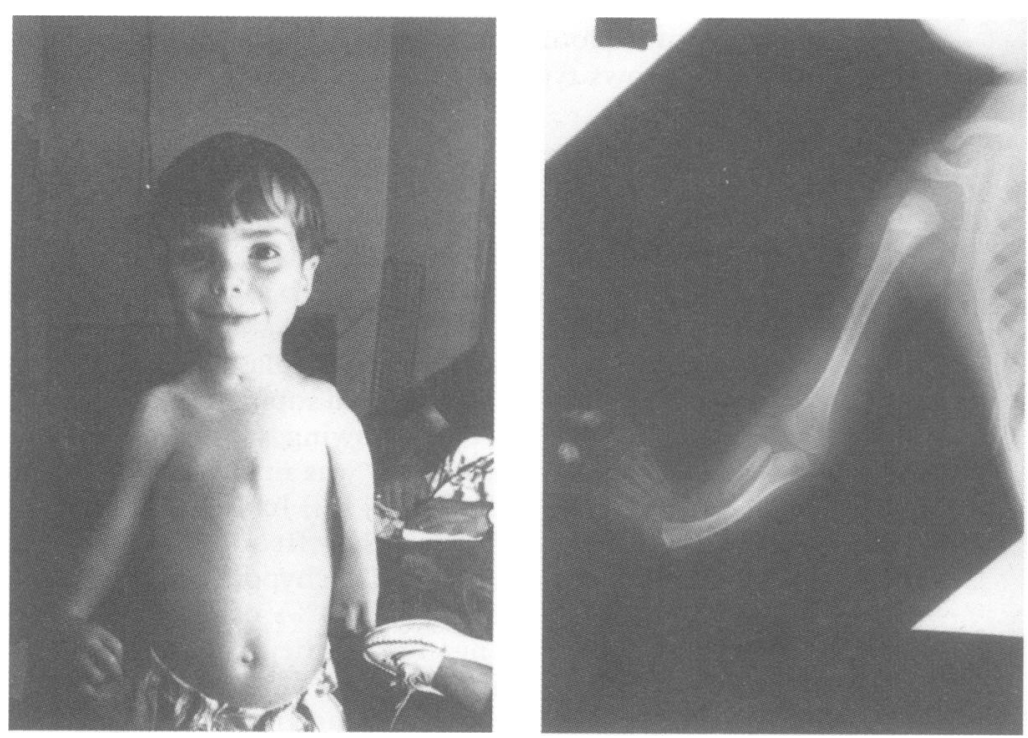

Figure 2 Photograph and $x$ ray of severely affected child showing left radial aplasia, ulnar aplasia, and hypoplastic humerus, and right radial hypoplasia and absent first ray.
Reduced shoulder movement, particularly abduction, was found. Hypoplasia of the overlying shoulder girdle musculature, especially the pectoralis major and the deltoids, was common.

Asymmetry. Abnormalities of the upper limb were always bilateral and often asymmetrical $(69.5 \%)$. Where this was the case the left side was affected more than the right in $90.6 \%$ of cases and the right more than the left in $9.4 \%$. Fig 1B shows typical hands with absence of the left thumb and a right sided triphalangeal thumb. In fig 2 a severely affected child has phocomelia of the left arm but less severe radial aplasia on the right.

\section{Isolated cases}

The spectrum of abnormalities differed in the small group of isolated cases (table 3). In particular, four patients had predominantly ulnar aplasia with involvement of the ulnar ray of the hand. One child had a unilateral transverse reduction anomaly of the second to fifth fingers with hypoplasia of the thumb and radial and ulnar hypoplasia, an anomaly not seen in any familial cases. Five patients had exclusively unilateral defects. In general, abnormalities in isolated cases were more severe. For example, $73 \%$ of the isolated cases had aplasia of the thumb as opposed to $43 \%$ of familial cases, a greater proportion had radial and ulnar involvement, and two (18\%) had bilateral phocomelia. In total, seven of the isolated cases were atypical for Holt-Oram syndrome as compared with the abnormalities seen in the familial cases. Full details of these are given in table 4 .

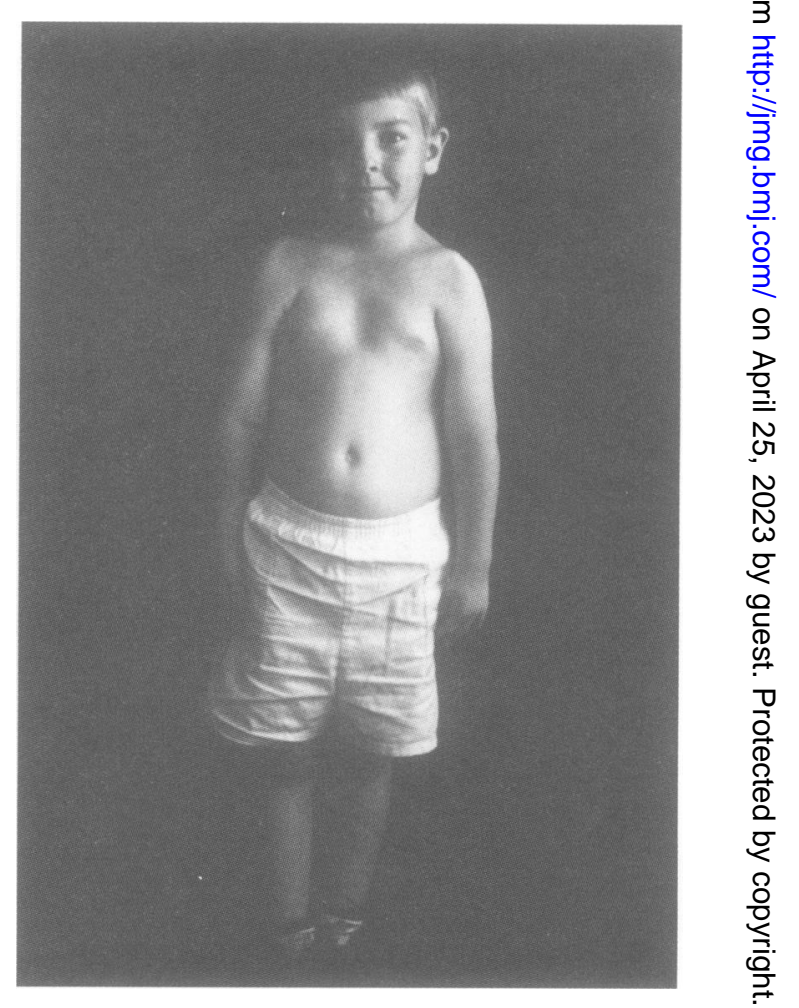

Figure 3 Typical shoulder abnormalities in HOS.

Narrow sloping shoulders, loss of usual contour owing to hypoplasia of the head of the humerus, prominent lateral third of clavicle, hypoplasia of pectoralis major, and mild pectus excavatum. 
Table 4 Details of seven atypical cases

\begin{tabular}{llll}
\hline Case No & Cardiac abnormality & Predominant skeletal abnormality \\
\hline 1 & Isolated & $\begin{array}{l}\text { Atrial septal defect } \\
\text { Ventricular septal defect } \\
\text { Pulmonary stenosis }\end{array}$ & Unilateral ulnar aplasia \\
& & Ventricular septal defect & \\
2 & Isolated & Aortic stenosis & Unilateral ulnar aplasia \\
& Isolated & Dextrocardia & Unilateral radial aplasia \\
4 & Isolated & Atrial septal defect & Unilateral digital \\
& & Ventricular septal defect & reduction defect \\
5 & Isolated & Aortic stenosis & Unilateral radial aplasia \\
6 & Isolated & Tetralogy of Fallot & Bilateral radial aplasia \\
7 & Isolated & Tetralogy of Fallot & Bilateral radial aplasia \\
\hline
\end{tabular}

Table 5 Cardiac abnormalities in 55 cases of HOS

\begin{tabular}{|c|c|c|}
\hline \multirow[t]{2}{*}{ Defect } & \multicolumn{2}{|c|}{ No of affected (\%) } \\
\hline & $\begin{array}{l}\text { Total } \\
44 \text { familial }\end{array}$ & $\begin{array}{l}\text { Total } \\
11 \text { isolated }\end{array}$ \\
\hline $\begin{array}{l}\text { Structural } \\
\text { Secundum atrial septal defect } \\
\text { Ventricular septal defect } \\
\text { Mitral valve prolapse } \\
\text { Tetralogy of Fallot } \\
\text { Aortic stenosis } \\
\text { Primum atrial septal defect } \\
\text { Patent ductus arteriosus } \\
\text { Sinus venosus atrial septal defect } \\
\text { Dextrocardia } \\
\text { Pulmonary stenosis }\end{array}$ & $\begin{array}{r}15(34) \\
11(25) \\
3(7)\end{array}$ & $\begin{array}{ll}5 & (45) \\
4 & (36) \\
& \\
2 & (18) \\
2 & (18) \\
& \\
1 & (9) \\
1 & (9) \\
1 & (9) \\
1 & (9)\end{array}$ \\
\hline ECG abnormality only & 17 (39) & $0 \quad(0)$ \\
\hline Normal heart & 4 (9) & $0 \quad(0)$ \\
\hline
\end{tabular}

CARDIAC ABNORMALITIES (TABLE 5)

Familial cases

Full cardiac details were available for 55 patients and $95 \%$ had evidence of cardiac involvement. Only two patients had normal clinical examination, ECG, and echocardiography. Of the familial cases, $25(57 \%)$ had a structural heart lesion, $22(50 \%)$ had a septal defect, 15 $(34 \%)$ an ASD, and $11(25 \%)$ VSD, including four patients with both. One patient had a complete atrioventricular septal defect and complete heart block. Three cases had mitral valve prolapse (MVP): two from the same family had MVP and first degree heart block and one patient had MVP, an ASD, and complete heart block (CHB). In total, three patients had complete heart block, two with septal defects and one without. Seventeen (39\%) had no structural defect but had an abnormal ECG with evidence of conduction defect (table 6). The commonest ECG abnormality was first degree heart block (PR interval $>0.2 \mathrm{sec}$ ) which was seen in $71 \%$. Right and left bundle branch block, left axis deviation, and bradycardia were also seen. The majority ( $85 \%$ ) had an asymptomatic cardiac lesion. Sixteen $(38 \%)$ patients required cardiac surgery for correction of their

\begin{tabular}{lc}
$\begin{array}{l}\text { Table } 6 \text { ECG findings in } 17 \text { patients } \\
\text { lesion }\end{array}$ \\
\hline ECG & Affected (\%) structural \\
\hline Long PR interval & $12(71)$ \\
Bradycardia & $6(35)$ \\
Left axis deviation & $7(41)$ \\
Right axis deviation & $8(47)$ \\
Left bundle branch block & $2(12)$ \\
P mitrale & $1(6)$ \\
Complete heart block & $1(6)$ \\
\hline
\end{tabular}

cardiac defect; of these 11 required surgery in childhood and five were operated on in adult life. Ten had an asymptomatic structural lesion (VSD or MVP). All three patients with complete heart block became symptomatic and required insertion of a pacemaker.

Detailed family histories showed that one affected relative had died postoperatively following closure of an ASD. Three patients from one family had died suddenly of undiagnosed heart abnormality. Necropsy on one, a child aged 6 months, showed a large undiagnosed ASD. No postmortem information was available on the other two cases who died suddenly.

\section{Isolated cases}

By definition all isolated cases had a structural cardiac lesion. Five patients had an ASD, two with ASD alone, two with ASD and a VSD, and one with ASD and pulmonary stenosis (PS). Two further patients had a VSD, one of whom also had aortic stenosis (AS), and two cases had tetralogy of Fallot. There was one case with a sinus venosus ASD, one with patent ductus arteriosus (PDA), and one case of dextrocardia with otherwise normal cardiac anatomy.

ASSOCIATED ABNORMALITIES

Eighteen $(41 \%)$ of the familial patients had a pectus deformity of whom 15 had an underlying cardiac defect. A number of non-cardiac, nonskeletal abnormalities were also observed, most particularly in the eyes. Sixteen patients wore glasses for a refractive error, five had a squint, and two had Duane anomaly. Skin findings included multiple pigmented naevi (1), large café au lait pigmentation (1), haemangioma (1), and accessory nipple (1).

\section{Genetic aspects}

MODE OF INHERITANCE

The pedigrees were consistent with autosomal dominant inheritance with many examples of male to male transmission and no statistically significant difference between the numbers of affected males and females. Twenty two affected parents had a total of 36 affected and 36 unaffected offspring.

No parental age effect was observed. This was assessed by comparing the mean parental age of sporadic cases with the mean general population parental ages. The mean paternal and maternal ages in the study were 29.6 years (range 26-35 years) and 27.6 years (range 25-35 years) respectively, as compared with the general population figures of $30 \cdot 19$ and $27 \cdot 15$ years respectively.

Penetrance was complete. Careful examination of all 17 obligate heterozygotes showed clinically detectable abnormalities.

Biological fitness was calculated from the numbers of offspring born to affected and unaffected subjects. Twelve affected parents had 13 unaffected sibs. The affected parents had 24 offspring, indicating that there was no reduction in fitness. 
Table 7 Correlation between severity scores for cardiac and skeletal abnormality

\begin{tabular}{lllllll}
\hline & \multicolumn{7}{c}{ Skeletal score } \\
\cline { 3 - 7 } & & 0 & 1 & 2 & 3 & 4 \\
\hline Cardiac score & 0 & 0 & 1 & 0 & 0 & 0 \\
& 1 & 0 & 7 & 7 & 3 & 0 \\
& 2 & 0 & 2 & 5 & 3 & 0 \\
& 3 & 0 & 2 & 3 & 9 & 2 \\
& 4 & 0 & 0 & 0 & 0 & 0 \\
\hline
\end{tabular}

Spearman rank $r=0.4894, p=0.001$.

SEVERITY

When scored separately, skeletal and cardiac abnormalities showed a statistically significant positive correlation (table 7). Although only two of the total number of affected patients $(4.5 \%)$ had severe phocomelia, $39 \%$ patients had a skeletal severity score of $\geq 3$ indicating a serious reduction anomaly of the upper limb; $34 \%$ had abnormalities of the forearms and hands only and $27 \%$ had only minor abnormalities of the hands. For cardiac abnormalities $36 \%$ scored 3 , indicating a structural lesion requiring surgery or symptomatic arrhythmia, $23 \%$ scored 2 denoting

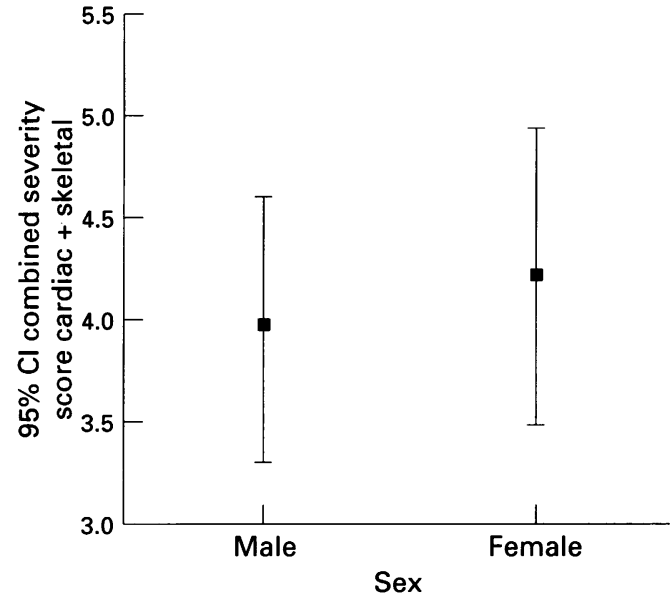

Figure 4 Mean combined severity score with 95\% confidence interval for 22 females and 22 males showing no difference in severity. (Mann-Whitney $U=221, p=$ 0.52.)

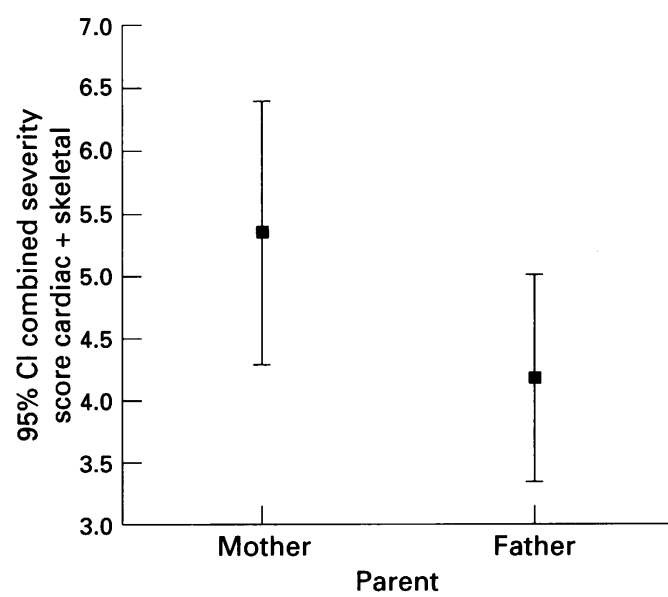

Figure 5 Maternal effect in HOS. Mean combined severity score for 11 offspring of affected fathers showing greater severity among offspring of affected mothers. (Mann-Whitney $U=305, p=0.0473$.)
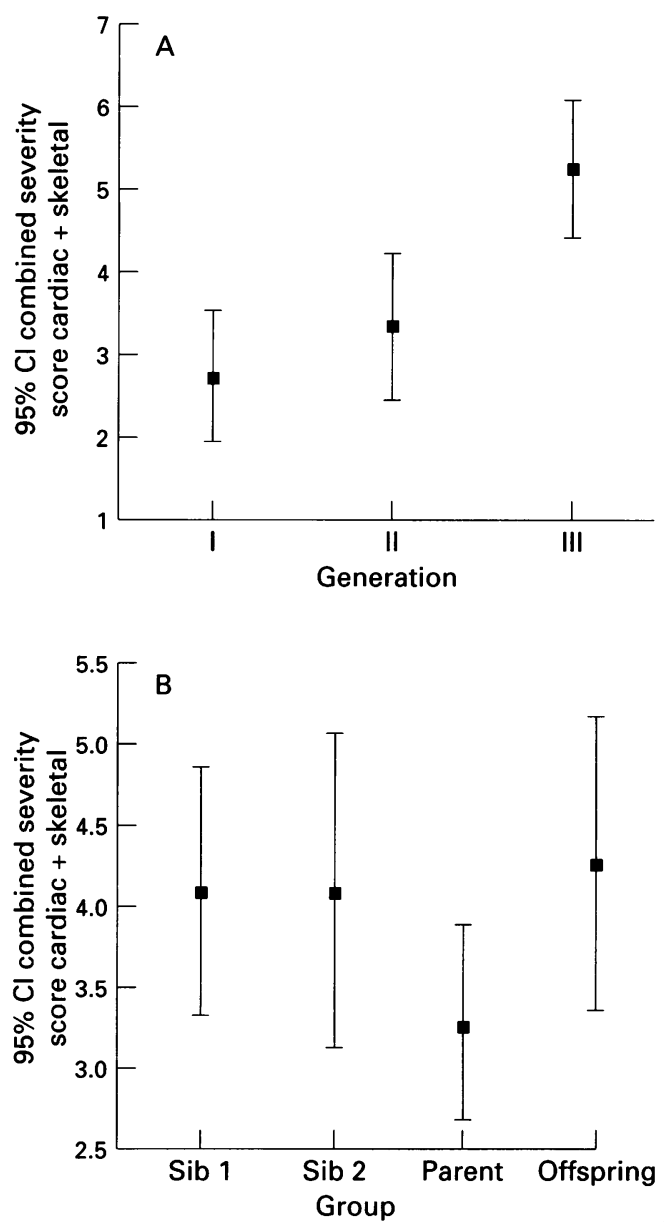

Figure 6 Evidence for anticipation in HOS. (A) Mean combined severity score for nine three generation families showing significant increase in severity in third generation. Kruskall Wallis $\chi^{2}=10 \cdot 89, p=0 \cdot 0043$. (B) Mean combined severity score for sib pairs compared to parent-offspring pairs showing greater correlation between sibs than between parent and offspring.

an asymptomatic structural defect, and 39\% scored 1 owing to an ECG abnormality.

There was no difference in severity between males and females (fig 4). Mean scores for offspring of affected mothers were greater than for offspring of affected fathers (fig 5). Analysis of severity of abnormalities in different generations within a family showed increasing severity in successive generations with a significant increase in severity from generation I to III (fig 6A). There appeared to be a greater correlation between severity in sib pairs than between parent and offspring (fig 6B).

\section{Discussion}

In this study we have reviewed the clinical and genetic features of HOS based on the largest known series, consisting of 72 patients, 57 of whom have been personally examined. This has allowed us to define the clinical phenotype and delineate the spectrum of abnormalities seen in familial cases. In this paper we have focused particularly on those clinical features which help to distinguish the diagnosis in isolated cases and those which enable affected parents to be alerted to the range of severity likely to be seen in future affected children. 
Table 8 Minimal diagnostic criteria for Holt-Oram syndrome

Radial ray defect
Septal defect (atrial or ventricular) or AV block in at least one family defect (atr family member

\section{LIMB ABNORMALITIES}

These involved primarily the radial ray. Proximal abnormalities of the arm and forearm were always accompanied by distal abnormalities in the hand, though the thumb was not necessarily abnormal. The shoulders were often involved even when involvement of the hands was minor. This feature seems to be specific to HOS and is not seen in cases of isolated radial ray defects, so the presence of a relatively subtle abnormality such as narrow sloping shoulders is a useful diagnostic pointer. Characteristically there was asymmetry of the limb abnormalities with a tendency for the left side to be more affected than the right. This contrasts with other radial ray defects which generally show right sided preponderance. ${ }^{11}$ Asymmetry is otherwise unusual for single gene disorders affecting the upper limb.

\section{CARDIAC ABNORMALITIES}

The incidence of cardiac defects (95\%) was similar to that seen in previous studies. ${ }^{2}$ While ASD was the structural lesion in the first family described, ${ }^{1}$ subsequent reports have included VSD and other defects. ${ }^{2-9}$ Five families in this study had no ASD. For example in one family a father with a conduction abnormality but no septal defect had two sons both of whom had a VSD and the same conduction disturbance. In another family a father with a conduction abnormality had a daughter with a VSD. All had radial ray abnormalities which were indistinguishable from families with an ASD. Following localisation of a gene for HOS to $12 \mathrm{q}$, analysis in these two families was consistent with linkage to this locus. This supports the notion that an ASD is not a requirement for the diagnosis.

All families had at least one member with a septal defect. First degree heart block was the commonest defect and may be seen with or without a septal defect. Two affected subjects from one family showing linkage to $12 \mathrm{q}$ had mitral valve prolapse in conjunction with first degree heart block. Mitral valve prolapse has previously been described in HOS. ${ }^{29}$ Seven patients had a combination of left axis deviation with first degree heart block. This ECG pattern may be seen in families with dominantly inherited non-syndromic ASD. ${ }^{12}$ A conduction defect may therefore be a forme fruste of HOS, possibly reflecting previous spontaneous closure of a septal defect. None of the rarer cardiac conditions seen in the isolated group and reported previously in isolated cases, for example, tetralogy of Fallot, ${ }^{13}$ was seen in the familial group in whom the most complex defect was an atrioventricular septal defect.

Data from this study have enabled us to define the HOS phenotype based on the features seen in familial cases and to set minimal diagnostic criteria (table 8). It has become evident that a number of isolated cases have features outside this spectrum and possibly represent other heart-hand associations.

DIFFERENTIAL DIAGNOSIS

The differential diagnoses include the dominantly inherited heart-hand syndromes. Hearthand syndrome II (Tabatznik) involves the combination of type $\mathrm{D}$ brachydactyly with supraventricular tachycardia. ${ }^{14}$ Patients may also have mild facial dysmorphism and mild mental retardation. Ruiz De La Fuente and Prieto $^{15}$ described heart-hand syndrome III with type $C$ brachydactyly plus sick sinus syndrome. The long thumb brachydactyly syndrome described by Hollister and Hollister ${ }^{16}$ shows similarities to HOS. There is dominant inheritance of a long thumb owing to elongation distal to the PIP joint with index finger brachydactyly, clinodactyly, narrow shoulders owing to short clavicles, and pectus excavatum. The cardiac abnormality is a conduction defect. There is also rhizomelic limb shortening.

Isolated cases of HOS need to be distinguished from recessive conditions which include heart-hand abnormalities, for example, thrombocytopenia-absent radius (TAR).${ }^{17}$ This differs from HOS in that radial aplasia is seen with the thumb present. In HOS radial aplasia would invariably be accompanied by hypoplasia or absence of the thumb. ASD may be seen and also tetralogy of Fallot. A number of other abnormalities may be found in TAR, including involvement of the lower limb, which are not seen in HOS. Radial ray defects are well recognised in Fanconi syndrome ${ }^{18}$ and specific investigation to exclude chromosomal breakage is required. Radial defects in the sporadic VACTERL association are more usually unilateral. ${ }^{19}$ Radial defects occur with Duane anomaly in the DR or Okihiro syndromes as well as being reported in HOS. ${ }^{20}$ Two patients (mother and son) from this series had Duane anomaly and HOS. Both had cardiac and upper limb involvement. There was no history of deafness.

\section{VARIATION IN EXPRESSION}

Our observations have confirmed previous reports of marked intra- and interfamilial variation with cardiac involvement varying from asymptomatic arrhythmias to large or multiple septal defects leading to death in infancy. Skeletal defects ranged from minor features such as clinodactyly or hypoplasia of the thenar eminence to severe reduction defects of the upper limb. In larger families there was evidence of a specific intrafamilial pattern as has been described previously. ${ }^{21} 22$ Three families showed a tendency to more severe cardiac involvement and mild limb abnormalities, whereas 12 showed more severe limb defects and less severe cardiac involvement.

\section{INCIDENCE OF SEVERE ANOMALIES}

Families seeking information regarding HOS usually want to know both the spectrum of 
the condition and the likelihood of serious abnormality. In this study one in three cases had a significant reduction deformity of the upper limb although only 1 in 22 had phocomelia. The only previous estimate of the incidence of phocomelia was 1 in $10 .^{3}$ This difference may reflect underascertainment of milder cases in previous studies. The most severe heart cases in cardiac terms were three premature deaths and two children who required surgery in the first year of life because of severe cardiac failure. Many septal defects either did not require treatment or, in the case of ASD, were treated electively in childhood or adulthood.

A statistically significant correlation was observed between the severity of limb and heart abnormalities in a given person. No difference in severity between the sexes was observed. This is in contrast to previous studies which have shown greater severity in females. ${ }^{38}$

GENETIC ASPECTS

The pedigrees were clearly indicative of autosomal dominant inheritance. A previous finding of abnormal segregation with more affected than unaffected offspring born to affected parents ${ }^{8}$ was not confirmed. It has been suggested in previous studies that abnormal segregation is the result of maternal fetal loss. ${ }^{2324}$ No such effect was observed in this study.

Penetrance was found to be complete. Although $x$ rays sometimes showed additional findings, all obligate heterozygotes showed clinical abnormalities on detailed examination. No examples of non-penetrance or gonadal mosaicism were encountered. Previous reports of the proportion of isolated cases attributable to new mutations vary from 0.3 to 0.85 . Of the cases referred to in this study only $8 \%$ were considered to be sporadic after examination of both parents and investigation with $x$ ray, ECG, and echocardiography. This lower figure may reflect incomplete ascertainment because of preferential referral of families for linkage analysis in our study. In three cases referred with no significant family history, clinical abnormalities were found in one of the parents.

\section{ANTICIPATION}

Several reports of families with HOS have mentioned an observed tendency to increasing severity of abnormalities in successive generations. ${ }^{462425} \mathrm{McKusick}^{26}$ was the first to report this in a family in which the grandparent had an ASD and triphalangeal thumbs, the parent had an ASD and absent thumbs, and the grandchild was born with a VSD and bilateral phocomelia. We examined this phenomenon in this study. Although families with three or more affected generations showed increasing severity of both skeletal and cardiac abnormalities as measured by severity scores (fig 6A) this is not in itself proof of anticipation. We would expect a degree of ascertainment bias since previous generations are often detected retrospectively and families are more likely to be identified if the index case is severe. Furthermore, in a
Table 9 Severity of skeletal defect as a function of cardiac defect

\begin{tabular}{ll}
\hline Cardiac defect & $\begin{array}{l}\text { Mean severity score } \\
\text { Skeletal defect }\end{array}$ \\
\hline Atrial septal defect & $2 \cdot 66$ \\
Ventricular septal defect & $2 \cdot 28$ \\
No structural defect & $1 \cdot 89$
\end{tabular}

dominant disorder with a severe phenotype one would expect to see such an increase in severity since mildly affected cases are more likely to reproduce, and following the birth of a severely affected child family size is restricted. However, fig $6 \mathrm{~B}$ indicates that there is a greater correlation between offspring than between parent and offspring, which is supportive evidence for anticipation. The mean severity score for each generation increased significantly although not all individual meioses led to an increase in severity score. Maternal meioses were never accompanied by a decrease in severity. However several paternal meioses did lead to a decrease in severity as measured by this method. This does not in itself rule out anticipation, as similar observations have been made in myotonic dystrophy where the proposed underlying genetic mechanism is a "retreat of the triplet repeat". ${ }^{27}$

The evaluation of anticipation and a parental effect in a genetic disorder usually involves documentation of age of onset. This approach cannot be applied to a congenital abnormality for which ranking or grading of severity for statistical analysis is necessary. Complete objectivity in clinical assessment of severity is difficult to achieve. However, our observations are consistent with both anticipation and a maternal effect although we recognise that confirmation or otherwise awaits isolation and characterisation of the HOS gene(s).

Meanwhile prospective parents can be alerted to the fact that a child born with HOS to an affected parent has a 1 in 3 chance of having a severe reduction abnormality of the upper limb with a 1 in 22 risk of phocomelia. If an ASD is present there is a greater risk of a serious limb abnormality than if a VSD or conduction defect occurs alone (table 9). Severity is likely to be greater if the transmitting parent is female. In our study there were no cases of severe limb abnormality occurring in isolation. Therefore the detection of a severe reduction defect before or after birth indicates that there is a high chance that a structural cardiac lesion will also be present.

The authors with to thank the clinicians who allowed us to approach their patients including Dr $M$ Baraitser, Professor J Burn, Dr $N$ Dennis, Professor D Donnai, Dr P Farndon, Professor P Hareer Dr H Hughes, Dr S Huson, Dr R Mueller Drof V Murday, Dr O Quarrell, Dr J Sampson, Dr J Tolmie, and Dr V Murday, Dr O Quarrell, Dr J Sampson, Dr J Tolmie, and the late Dr David Siggers; Mr K Hosie for his help visiting families; Dr E Blank for his helpful comments regarding this manuscript; Dr C A Parkin and Dr K Martin for the cytogenetic analyses; and Mrs R Goodwin for typing the manuscript. We are most grateful to the families and patients with HOS fo their encouragement and support. This research was supporte by the British Heart Foundation and the Trent Health Directorate of Research and Development.

1 Holt $M$, Oram S. Familial heart disease and skeletal manifestations. Br Heart F 1960;22:236-42.

2 Smith AT, Sack GH, Taylor GJ. Holt-Oram syndrome. $f$ Pediatr 1979;95:538-43. 
3 Holmes LB. Congenital heart disease and upper-extremity deformities. A report of two families. $N$ Engl f Med 1965; 272:437-44.

4 Gardner RJM, Buckfield PM, Veale AMO. A girl with severe expression of the Holt-Oram syndrome. Clin Genet 1973 4:417-21.

5 Sanchez-Cascos A. Holt-Oram syndrome. Acta Paediatr Scand 1967;56:313-17.

6 Lewis KB, Bruce RA, Baum D, Motulsky AG. The upper limb-cardiovascular syndrome. An autosomal dominan genetic effect on embryogenesis. $7 A M A$ 1965;193:1080-6.

7 Terrett JA, Newbury-Ecob E, Cross GS, et al. Holt-Oram syndrome is a genetically heterogeneous disease with one locus mapping to human chromosome 12q. Nature Genet 1994;6:401-4.

8 Gall JC, Stern AM, Cohen MM, Adams MS, Davidson RT. Holt-Oram syndrome: clinical and genetic study of RT. Holt-Oram syndrome: clinical and genetic study

9 Gladstone I, Sybert VP. Holt-Oram syndrome: penetrance of the gene and lack of maternal effect. Clin Genet 1982; of the gene

10 Hall JG, Froster-Iskenius UG, Allanson JE. Handbook of normal physical measurements. Oxford: Oxford University Press, 1989

11 Carroll RE, Louis DS. Anomalies associated with radial dysplasia. F Pediatr 1974;84:409-11.

12 Bosi G, Sensi A, Calzolavi E, Scorrano M. Familial atria septal defect with prolonged atrioventricular conduction. Am $\mathcal{F}$ Med Genet 1992;43:641.

13 Brans YW, Lintermans JP. The upper limb cardiovascular syndrome. Am f Dis Child 1972;124:779-83.

14 Silengo MC, Biagioli M, Guala A, Lopez-Bell G, Lala R. Heart-hand syndrome II. A report of Tabatznik syndrome with new findings. Clin Genet 1990;38:105-13.
15 Ruiz De La Fuente S, Prieto F. Heart-hand syndrome III. A new syndrome in three generations. Hum Genet 1980; A n:43-7.

16 Hollister DW, Hollister WG. The "long thumb" brachydactyly syndrome. Am 7 Med Genet $1981 ; 8: 5-16$

17 Hall JG. Thrombocytopenia and absent radius (TAR) syndrome. $\mathcal{F}$ Med Genet 1987;24:79-83.

18 Glanz A, Fraser FC. Spectrum of anomalies in Fanconi anaemia. $\mathcal{F}$ Med Genet 1982;19:412-16.

19 Khoury MJ, Cordero JF, Greenberg F, James LM, Erickson JD. A population study of the VACTERL association. Pediatrics $1983 ; 71: 815-20$.

20 Chang CHJ. Holt-Oram syndrome. Radiology 1987;88:47083.

21 Basson CT, Cowley GS, Solomon SD, et al. The clinical and genetic spectrum of the Holt-Oram syndrome (hearthand syndrome). $N$ Engl $\mathcal{F}$ Med 1994;330:885-91.

22 Kaufman RL, Rimoin DL, McAlister WH, Hartmann AF Variable expression of the Holt-Oram syndrome. Am $\mathcal{F}$ Dis Child 1974;127:21-5.

23 Brons JTJ, Van Geijn HP, Wiladimiroff JW, et al. Prenatal ultrasound diagnosis of Holt-Oram syndrome. Prenat Diagn 1988;8:175-81.

24 Van Regemorter N, Haumont D, Kirkpatrick C, et al. Holt-Oram syndrome mistaken for thalidomide embryopathy - embryological considerations. Eur $\mathcal{F}$ Pediatr 1982;138:77-80

25 Temtamy SA, McKusick VA. The genetics of hand malformations. Birth Defects 1978;XIV(3):117-33.

26 McKusick VA. Medical genetics. F Chronic Dis 1961;14 1-198.

27 Brook JD. Retreat of the triplet repeat. Nature Genet 1993; 3:279-87. 